ARTICLE

https://doi.org/10.1038/s41467-019-08636-w

\title{
Soil carbon sequestration accelerated by restoration of grassland biodiversity
}

Yi Yang ${ }^{1}$, David Tilman (10 ${ }^{1,2}$, George Furey ${ }^{1} \&$ Clarence Lehman $^{1}$

Agriculturally degraded and abandoned lands can remove atmospheric $\mathrm{CO}_{2}$ and sequester it as soil organic matter during natural succession. However, this process may be slow, requiring a century or longer to re-attain pre-agricultural soil carbon levels. Here, we find that restoration of late-successional grassland plant diversity leads to accelerating annual carbon storage rates that, by the second period (years 13-22), are 200\% greater in our highest diversity treatment than during succession at this site, and $70 \%$ greater than in monocultures. The higher soil carbon storage rates of the second period (years 13-22) are associated with the greater aboveground production and root biomass of this period, and with the presence of multiple species, especially C4 grasses and legumes. Our results suggest that restoration of high plant diversity may greatly increase carbon capture and storage rates on degraded and abandoned agricultural lands.

\footnotetext{
${ }^{1}$ Department of Ecology, Evolution, and Behavior, University of Minnesota, St. Paul, MN 55108, USA. ${ }^{2}$ Bren School of Environmental Science and Management, University of California, Santa Barbara, CA 93106, USA. Correspondence and requests for materials should be addressed to D.T. (email: tilman@umn.edu)
} 
S oils store climatically significant amounts of carbon (C) as soil organic matter, globally about 2.3 times greater than the $\mathrm{C}$ in atmospheric $\mathrm{CO}_{2}$ and 3.5 times greater than the $\mathrm{C}$ in all living terrestrial plants ${ }^{1}$. However, prolonged cultivation accelerates the decomposition of soil organic matter and can cause the loss of $20-67 \%$ of the soil $C$ in an agricultural field ${ }^{2-4}$. Between 1850 and 1998, global agricultural cultivation led to the release of $\sim 78 \mathrm{Gt}$ of $\mathrm{C}$ from soil as $\mathrm{CO}_{2}$ to the atmosphere ${ }^{4}$, with $\sim 133 \mathrm{Gt}$ of soil $\mathrm{C}$ so released since the beginning of agriculture ${ }^{5}$. Since the current global annual $\mathrm{CO}_{2}$ emissions from fossil fuels and all other sources are $\sim 10 \mathrm{Gt}$ of $\mathrm{C}^{6}$, soil $\mathrm{C}$ sequestration has thus been proposed as a plausible partial climate mitigation strategy that might buy time while low-carbon technologies are being developed and adopted ${ }^{7}$. Indeed, a recent international initiative has set a target of increasing global soil organic matter by $0.4 \%$ per year to help negate some greenhouse gas emissions ${ }^{8}$.

Abandoned agricultural lands have been a particular area of interest for carbon capture and storage ${ }^{9-12}$ because of their highpotential capacity for $\mathrm{C}$ sequestration ${ }^{8}$. An estimated $\sim 430$ million hectares of land globally has been cleared, cropped, degraded and then abandoned ${ }^{13}$. When agriculturally degraded lands are abandoned and undergo ecological succession, they remove atmospheric $\mathrm{CO}_{2}$ and sequester its $\mathrm{C}$ as soil organic matter ${ }^{7,14}$. However, this process may require a century or more for soil carbon to re-attain pre-agricultural levels ${ }^{15-17}$. Since the original soils of these abandoned lands had been formed by native, latesuccessional and often highly diverse ecosystems, we decided to test the possibility that rapid restoration of late-successional plant diversity might accelerate soil $\mathrm{C}$ storage above the rates observed during natural succession ${ }^{18}$. Here, we report how the experimental restoration of different levels of late-successional plant diversity on abandoned agricultural land impacted the rate of soil C storage across 22 years, and how these rates compare to those observed during succession at the same site.

During the ecological succession that follows abandonment of agricultural lands at our research site in Minnesota, USA, 50 years are required for the perennial plant species that dominate nearby native grassland ecosystems to become dominant ${ }^{19,20}$. During the first decades of succession, abandoned agricultural lands are dominated by annual plants and fast-growing and fastdispersing $\mathrm{C} 3$ plant species ${ }^{20}$. These species are gradually outcompeted by late-successional perennial prairie $\mathrm{C} 4$ grass species that are strong competitors for soil nitrogen because of high-root mass, but that are slow to arrive in a field, and slow to spread across it, because they have low-dispersal rates and low-growth rates $^{21-23}$. Because the $\mathrm{C} 3$ grass and forb species have both less roots and roots that, in a 1 year period, decomposed 55\% and
$138 \%$ faster, respectively, than did roots of the C4 grasses ${ }^{24}$, it seems plausible that soil $\mathrm{C}$ storage rates would increase once native $\mathrm{C} 4$ grasses attain dominance during succession. In contrast, our experiment, started in 1994 to understand effects of plant biodiversity, had effectively restored various levels of latesuccessional plant diversity in replicated plots planted on a highly degraded soil within 5 years. The plant diversity restoration treatments represent planting either $1,2,4,8$, or 16 species of perennial grassland plants common in nearby undisturbed native prairie, with $\sim 30$ replicate plots for each of these 5 levels of planted diversity ${ }^{25}$. All plots were sampled periodically for soil C, root $C$ and species abundances, with the upper layer of soil (0-20 $\mathrm{cm}$ for soil $\mathrm{C}$ and $0-30 \mathrm{~cm}$ for roots) sampled more frequently than deeper layers $(20-60 \mathrm{~cm}$ for soil $\mathrm{C}$ and $30-60 \mathrm{~cm}$ for roots) (see Methods). We report both soil $\mathrm{C}$ and root mass because numerous analyses have shown that grassland plots with higher root mass tend to accumulate soil $\mathrm{C}$ at greater rates ${ }^{24,26}$.

In our 22-year experiment, annual rates of soil carbon storage increased through time and, on average across all diversity treatments, were $\sim 90 \%$ greater in the second period (13-22 years) than in the first period (1-13 years). The highest diversity treatment had carbon storage rates in the second period (13-22 years) $\sim 200 \%$ greater than during succession at this site. Across the full time span, the highest diversity treatment stored $178 \%$ more $\mathrm{C}$ in soil than did the monocultures, demonstrating the potentially large carbon storage advantage that rapid restoration of high plant diversity may provide. These higher rates of soil carbon storage were strongly associated with the joint presence of $\mathrm{C} 4$ grasses and legumes in higher-diversity plots. Such plots also had greater aboveground production and root biomass. In total, our results suggest that both high plant diversity and the presence of specific combinations of plant functional traits may be needed to maximize the rate of below-ground carbon storage on degraded and abandoned agricultural lands.

\section{Results}

Soil carbon storage rates and plant diversity. We found that, at each experimentally imposed level of plant diversity, the average annual rate of $\mathrm{C}$ storage in soils, as quantified by $\Delta \mathrm{C} / \Delta t$ (units of $\mathrm{Mg}$ of $\mathrm{C} \mathrm{ha}^{-1} \mathrm{y}^{-1}$ ), was greater in the second period (13-22 years) of the experiment than in the first period (1-13 years; Fig. 1a, b). These accelerating rates of soil $\mathrm{C}$ sequestration were apparent for both the $0-20 \mathrm{~cm}$ depth soil profile (Fig. 1a) and the full $0-60 \mathrm{~cm}$ profile (Fig. 1b). On average over all diversities, annual storage rates for the second period were $88 \%$ and $253 \%$ greater than for the first period for the $0-60 \mathrm{~cm}$ and the $0-20 \mathrm{~cm}$ profiles, respectively. In addition, across the 5 times that the top $20 \mathrm{~cm}$ of soil was sampled
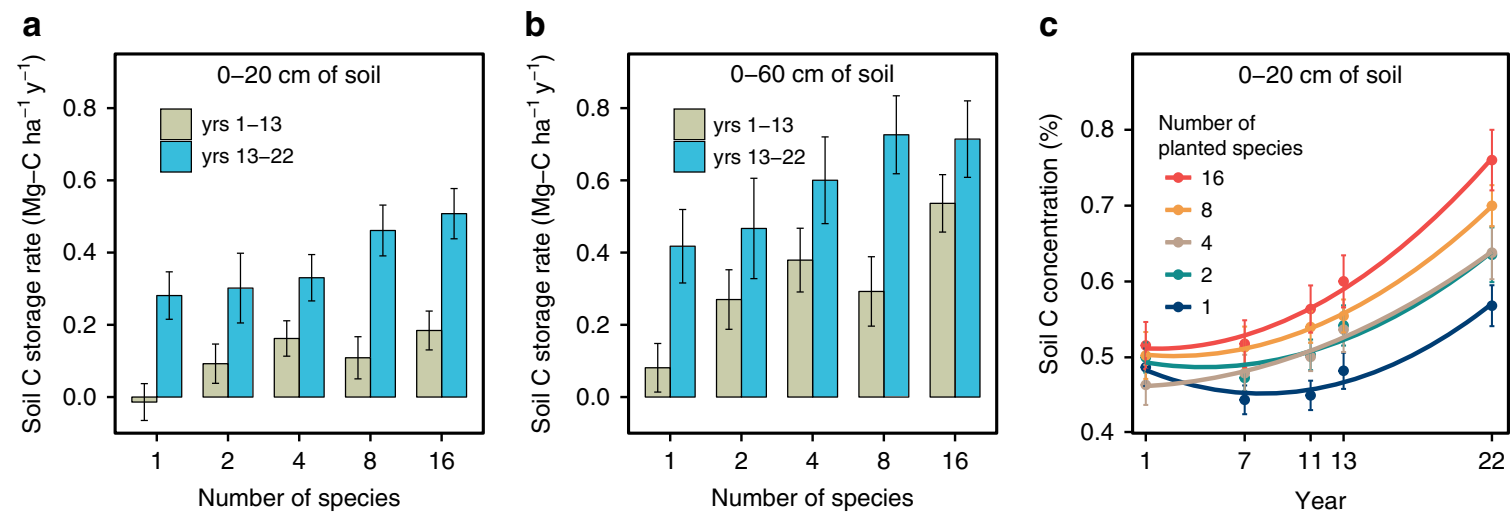

Fig. 1 Change in soil C over 22 years. a, b Average annual soil C storage rates over years 1-13 (green bars) and years $13-22$ (blue bars) in upper 20 cm of soil (a) and in upper $60 \mathrm{~cm}$ (b) (Supplementary Table 1). Bars are means with standard errors. c Dynamics of soil C concentration in upper $20 \mathrm{~cm}$ of soil for plots planted with 1, 2, 4, 8, or 16 perennial grassland species (Supplementary Table 2). Dots are means with standard errors; fitted curves are quadratic 

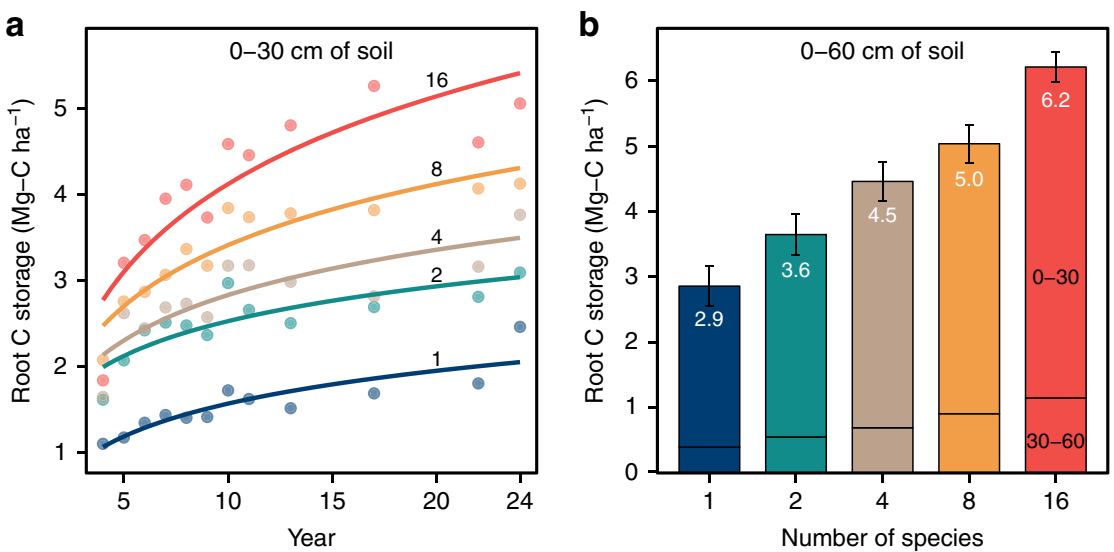

Fig. 2 Change in root $C$ over 24 years. a Change in root $C$ in upper $30 \mathrm{~cm}$ of soil under different experimentally imposed levels of plant species diversity. Dots indicate mean root $\mathrm{C}$ at a given year; curves fitted with log functions; the number on each curve indicates plant species diversity. $\mathbf{b}$ Total root $\mathrm{C}$ storage after 24 years of growth in upper $60 \mathrm{~cm}$ of soil. Numbers in white indicate mean total root $\mathrm{C}$ storage, error bars indicate standard errors, and numbers in black indicate soil depth increments $(\mathrm{cm})$

for $\mathrm{C}$, the time dynamics of soil $\mathrm{C}$ concentration at each level of plant diversity was best fit by quadratic equations curving upward (Fig. 1c), further demonstrating that rates of $\mathrm{C}$ sequestration accelerated through time.

Rates of soil $\mathrm{C}$ sequestration were greater at higher plant diversity (Fig. 1). Annual storage rates for the first period (1-13 years) for the $0-60 \mathrm{~cm}$ soil depth profile were $0.08( \pm 0.07), 0.27( \pm 0.08), 0.38$ $( \pm 0.09), 0.29( \pm 0.10)$, to $0.54( \pm 0.08) \mathrm{Mg}-\mathrm{Cha}^{-1} \mathrm{y}^{-1}$ in the 1-, 2-, $4-, 8-$, and 16-species treatments, respectively (Fig. 1b; Supplementary Table 1). For the second period (13-22 years), they increased to $0.42( \pm 0.10), 0.47( \pm 0.14), 0.60( \pm 0.12), 0.73( \pm 0.11)$, and 0.71 $( \pm 0.11) \quad \mathrm{Mg}-\mathrm{Cha}^{-1} \mathrm{y}^{-1}$, respectively (Fig. $1 \mathrm{~b}$; Supplementary Table 1). For the full 22-year duration of the experiment, when compared to means across all species in monocultures, higher plant biodiversity led to $60 \%, 115 \%, 115 \%$, and $178 \%$ greater soil C storage in the 2- to 16-species plots, respectively, for the $0-60 \mathrm{~cm}$ profile (Supplementary Table 3 ). When initial soil $\mathrm{C}$ levels are considered, annual soil $\mathrm{C}$ proportional growth rates $\left(\mathrm{dC} / \mathrm{d} t{ }^{\star} 1 / \mathrm{C}\right)$ were $0.6 \%, 1.0 \%, 1.3 \%, 1.3 \%$, and $1.6 \% \mathrm{y}^{-1}$ for the $1,2,4$, and 16 species treatments, respectively, across the full experimental duration for the $0-60 \mathrm{~cm}$ profile (Supplementary Table 4).

A linear mixed model showed that soil $\mathrm{C}$ concentration (logtransformed) for the $0-20 \mathrm{~cm}$ soil depth increased through time with the quadratic time term being positive and significant $(P<$ $0.0001)$, and also increased with the number of planted species $(P=0.0025)$, and had a positive time $\times$ diversity statistical interaction $(P<0.0001$; Fig. $1 \mathrm{c}$ and Supplementary Table 5). When comparing the annual soil $\mathrm{C}$ storage rates of the first period (1-13 years) to those of the second period (13-22 years) for the $0-60 \mathrm{~cm}$ soil depth (Fig. 1b), multiple regression (overall: $F_{3,300}=10.78, \quad P<0.0001, \quad r^{2}=0.10 ;$ Supplementary Table 6) showed that storage rates $\left(\mathrm{Mg}-\mathrm{Cha}^{-1} \mathrm{y}^{-1}\right)$ were higher in the second period $(P<0.0001)$, were positively associated with diversity (the number of planted species; $P=0.0002$ ), but the period $\times$ diversity interaction was not significant $(P=0.6939$; Fig. 1b). This same pattern held for soil $\mathrm{C}$ storage rates for these 2 periods for the $0-20 \mathrm{~cm}$ depth (overall: $F_{3,300}=19.26, P<0.0001$, $r^{2}=0.16$; Fig. 1a; Supplementary Table 7).

Aboveground and below-ground productivity and diversity. Root $\mathrm{C}$ and the amount of aboveground plant biomass produced each year (productivity) increased with plant diversity. After increasing, especially at higher plant diversity, for the first 8 years, aboveground productivity subsequently had year-to-year variation that corresponded with growing season precipitation and temperature conditions (Supplementary Fig. 1). In contrast, root mass $(0-60 \mathrm{~cm}$ depth), which was on average 5.5 times the mass of aboveground biomass, tended to increase throughout the 24 years, but at decelerating rates (Fig. 2a). By the 24th year of the experiment, plant roots in the $0-60 \mathrm{~cm}$ depth contained an average of $2.9( \pm 0.3) \mathrm{Mg}-\mathrm{Cha}^{-1}$ in monoculture plots and 6.2 $( \pm 0.2) \mathrm{Mg}^{-C \mathrm{ha}^{-1}}$ in 16-species plots (Fig. 2b). Most root $\mathrm{C}$ was concentrated in the upper $30 \mathrm{~cm}$ of soil, with $16-23 \%$ more root $\mathrm{C}$ between 30 and $60 \mathrm{~cm}$ for low- to high-diversity plots (Fig. 2b). A linear mixed model showed that root $C(0-30 \mathrm{~cm})$ increased with time, with the number of planted species, and with their positive interaction $(P<0.0001$ for all estimates; Supplementary Table 8). A linear mixed model showed that the root:shoot ratio (R:S; root biomass $(0-30 \mathrm{~cm}$ depth)/aboveground biomass) of plots was statistically independent of plant diversity $(P=0.0701)$, increased through time $(P<0.0001)$, was significantly higher when $\mathrm{C} 4$ grasses were present (least square mean; $\mathrm{R}: \mathrm{S}=5.0$ ) versus absent $(\mathrm{R}: \mathrm{S}=2.5 ; P<0.0001)$ and when $\mathrm{C} 3$ grasses were present $(\mathrm{R}: \mathrm{S}=4.0)$ versus absent $(\mathrm{R}: \mathrm{S}=3.6 ; P=0.0293)$, but was lower when legumes were present $(\mathrm{R}: \mathrm{S}=2.8)$ versus absent (R:S $=4.8 ; P<0.0001)$ and when nonlegume forbs were present $(\mathrm{R}: \mathrm{S}=3.4)$ versus absent $(\mathrm{R}: \mathrm{S}=4.2 ; P=0.0002$; Supplementary Table 9). For the last 5 years of the experiment, the average R:S ratio (0-30 cm soil depth) across all plots was 4.3 , and was 5.5 for 0-60 cm depth roots for the 3 years root biomass was sampled to the depth of $60 \mathrm{~cm}$ (in 2006, 2015, and 2017).

Comparison with natural succession in nearby old fields. During succession in abandoned agricultural fields at our site, annual and short-lived perennial plant species were dominant initially ${ }^{19}$. The native perennial plant species that dominate undisturbed grasslands at our site are rarely present during the first decade of succession, and colonize into and increase in abundance slowly through time, with native species and native $\mathrm{C} 4$ grasses comprising about $90 \%$ and $55 \%$, respectively, of the plant community abundance after $\sim 50-70$ years of succession ${ }^{19,20}$. Analysis of soil C along this chronosequence (based on 2000 plots from 21 agricultural fields abandoned at different times from 4 to 74 years ago), gives an annual rate of $\mathrm{C}$ storage of $0.17( \pm 0.05)$ $\mathrm{Mg}-\mathrm{Cha} \mathrm{h}^{-1} \mathrm{y}^{-1}$ for the $0-20 \mathrm{~cm}$ depth profile and suggests that this annual rate of soil $\mathrm{C}$ accumulation under natural succession is approximately constant across this 70 year period ${ }^{20}$. During the first period (1-13 years) of our experimental restoration, $C$ storage rates were $0.16( \pm 0.05), 0.11( \pm 0.06)$, and $0.18( \pm 0.05) \mathrm{Mg}_{-} \mathrm{C} \mathrm{ha}{ }^{-1}$ $\mathrm{y}^{-1}$ in the 4,8 , and 16 species treatments for the $0-20 \mathrm{~cm}$ depth 

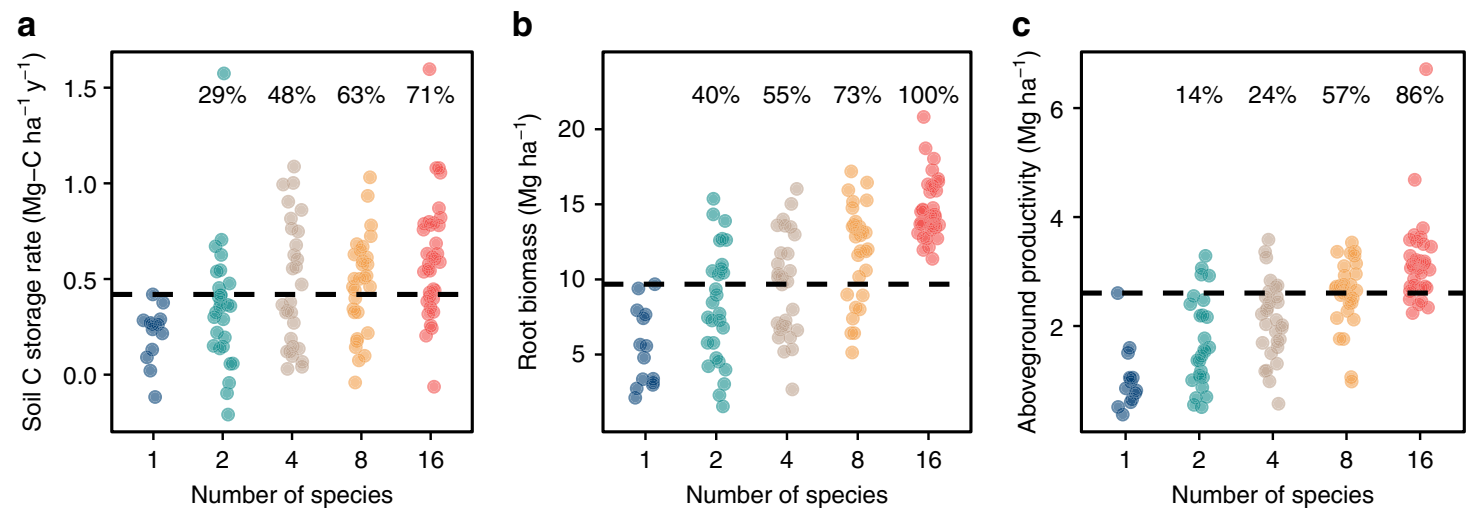

Fig. 3 Higher-diversity plots versus the best species in monoculture. a Soil C storage rate over the entire 22 years for the $0-60 \mathrm{~cm}$ soil profile. $\mathbf{b}$ Mean root biomass for the 0-60 cm soil profile (average of 2006, 2015, and 2017). c Mean productivity from 2012 to 2016. The numbers at the top of each panel are proportions of mixture plots surpassing the best performing monoculture species. Proportions increase with diversity for all three measures. Monocultures values are means of plots planted to a given species

profile (Supplementary Table 1), comparable to those of succession. However, during the second period (13-22 years), we observed an acceleration of soil $\mathrm{C}$ storage, with rates of 0.33 $( \pm 0.06), 0.46( \pm 0.07)$, and $0.51( \pm 0.07) \mathrm{Mg}-\mathrm{C} \mathrm{ha}^{-1} \mathrm{y}^{-1}$ in the 4, 8, and 16 species treatments for the $0-20 \mathrm{~cm}$ depths (Supplementary Table 1). These rates are $94 \%, 170 \%$, and $200 \%$ greater, respectively, than those observed during natural succession at our site. The magnitude of this effect suggests that active restoration of abandoned croplands to high diversity of late-successional plant species might triple the annual rate of soil $\mathrm{C}$ storage, and thus provide a potentially important climate moderating effect.

Biodiversity and sampling versus complementarity. Increases in biodiversity can impact ecosystem functioning because of sampling effects (the greater likelihood of the functionally best species being present at high diversity), or because of complementary interactions among species caused by their differing traits ${ }^{27}$. The signature of sampling effects is that high-diversity plots never perform significantly better than the single best species in monoculture. In contrast, the signature of complementarity is that, at higher diversity, an increasingly larger number of plots have functioning that exceeds that of the best species in monoculture 25,28 . Comparing higher diversity plots with the performance of the monocultures of the best species offers strong evidence for a complementarity effect, rather than a sampling effect (Fig. 3). For soil C storage rates, root biomass, and aboveground biomass yield, the proportion of 2-, 4-, 8-, 16species plots surpassing the best performing monoculture species (mean of plots with the same species) increases with diversity. In particular, the majority of 8- and 16-species plots outperformed the best monocultures for all 3 variables. For root biomass (Fig. 3b), all of the 16-species plots have higher biomass than the best monoculture species, demonstrating that no species on its own produces as much below-ground biomass as do the highest diversity plots. Although this analysis does not prove the underlying causative mechanisms, it demonstrates that soil carbon stores, root mass, and aboveground productivity are greater at higher diversity because of some form of interspecific interaction or complementarity, rather than a simple sampling effect.

Mechanisms explaining soil C storage. Soil C sequestration was positively associated with aboveground plant biomass and root biomass. A linear mixed model showed that soil $\mathrm{C}$ concentrations (as \%) in the upper $20 \mathrm{~cm}$ of soil were positively correlated with root biomass $(P=0.0004)$, time $(P<0.0001)$, and aboveground plant biomass $(P=0.0033$; Supplementary Table 10$)$. We further investigated which species may have contributed to soil C sequestration using species abundance data we have collected periodically since 2001. A multiple regression analysis of the soil C storage rate for the $0-60 \mathrm{~cm}$ soil profile from 1994 to $2016(\mathrm{Mg}$ $\left.\mathrm{C} \mathrm{ha}^{-1} \mathrm{y}^{-1}\right)$ as a function of mean species abundances over the past 10 years (2006-2015) showed soil C storage rates were significantly correlated with seven species $(P<0.05$, Supplementary Table 11), including three $C 4$ grass species, two legume species, a C3 grass species and a forb species. These results suggest that a diversity of plant functional traits were involved in soil C storage $^{24}$. Moreover, at each level of plant diversity, plots containing both one or more $\mathrm{C} 4$ grass species and one or more legume species had greater root biomass and soil carbon storage than did plots with $\mathrm{C} 4$ grasses but no legumes, and those with legumes but no C4 grasses (Fig. 4a, b) ${ }^{24}$. This may be because, of the four functional groups, C4 grasses have the greatest root mass (Fig. 4c), produce roots with the lowest decomposition rates (Fig. 4d), and are the dominant functional group $(45 \%$ of aboveground biomass). In contrast, legumes fix $\mathrm{N}$ but have lower root mass, and produce litter that decomposes more rapidly. When these differing traits are combined in a plot, we suggest that rates of soil $\mathrm{C}$ storage are elevated because $\mathrm{C} 4$ grasses can use $\mathrm{N}$ released by decomposing legume roots to produce above- and below-ground biomass that decomposes slowly, causing $\mathrm{C}$ to accumulate. Higher-diversity plots that contain more species of $\mathrm{C} 4$ grasses and legumes have more above- and below-ground biomass which likely contributes to their greater rates of $\mathrm{C}$ storage in soil.

\section{Discussion}

These results show that, during the second period (13-22 years) of our experiment, the active restoration of high-diversity latesuccessional plant communities caused soil $\mathrm{C}$ accrual to accelerate, with $C$ pools accumulating at a rate $2-3$ times that observed in natural succession at our site. We suggest that these elevated rates resulted from how rapidly we re-established, relative to succession, high-diversity communities populated with perennial plant species with high root:shoot ratios and low decomposition rates of these roots.

The increases in soil $\mathrm{C}$ sequestration rates that we observed following restoration of highly diverse plant communities suggest that similar studies should be performed in other sites to determine if or how differences in climate, soil type, plant functional traits may influence soil $\mathrm{C}$ storage rates on abandoned lands. It is important to note that the soils of our site have $>90 \%$ sand, loworganic matter $(\sim 0.5 \%)$, and limited horizon development, and 

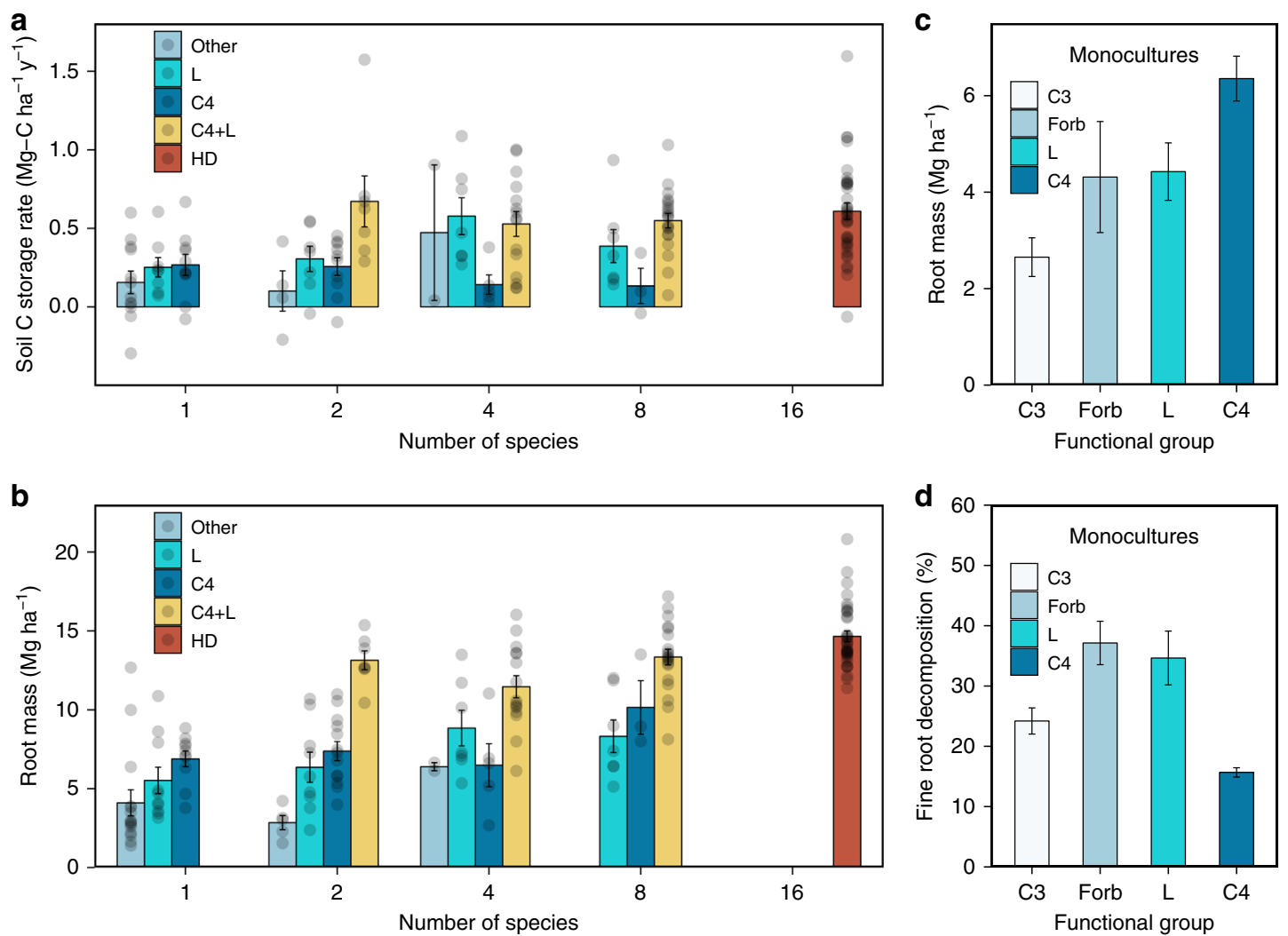

Fig. 4 Functional composition and traits influence root biomass and soil C storage. a Soil C storage rates over the entire 22 years for the 0-60 $\mathrm{cm}$ profile. b Mean root biomass for the $0-60 \mathrm{~cm}$ soil profile (average of 2006, 2015, and 2017). c Mean root biomass of different functional groups in monoculture plots (0-30 cm soil profile, average of 2006, 2015, and 2017). d Fine root decomposition percentage of different functional groups (measured after 10 months of field incubation, which included $\sim 5$ winter months ${ }^{54}$ ). In all panels, bars are means with standard errors. In $\mathbf{a}$ and $\mathbf{b}$, dots indicate plot results: C4-plots with at least one C4 but without legume; $L-$ plots with at least one legume but without C4; C4 $+\mathrm{L}-$ plots with at least one C4 and one legume; Other-forbs, C3, or woody; HD-16-species plots, which include both C4 and legume (of typically 3-4 species each). In $\mathbf{c}$ and $\mathbf{d}$ for monoculture plots, L means legume

were subject to herbicide, some soil removal, plowing and disking prior to planting. Moreover, our plots were weeded several times every year to retain their desired diversity and composition. As in other experiments ${ }^{29,30}$, weeds appeared much more frequently and in higher density in our lower-diversity plots. Weeding removes biomass, and thus might lower soil $\mathrm{C}$ storage rates. However, if competition with weeds reduces the productivity of the planted late-successional species ${ }^{31}$, weeding might increase soil $\mathrm{C}$ storage because of greater abundance of late-successional species. In a parallel experiment at our site, plots that had been planted with 32 late-successional grassland species and never weeded had remarkably similar rates of soil $C$ sequestration as our 16-species plots (Supplementary Fig. 2), suggesting that high diversity of late-successional species leads to high rates of soil $\mathrm{C}$ storage even without weeding. Finally, our experiment used native species, while nonnative and highly productive $\mathrm{C} 4$ grasses, such as Miscanthus, may also lead to high soil $\mathrm{C}$ sequestration rates $^{32}$. The use of non-native species, however, may pose risks of invasions that need to be better understood and considered ${ }^{33,34}$.

When compared with natural succession at our site, the high rates of soil carbon accumulation observed in our restored highdiversity grassland ecosystems suggest that immediately restoring degraded land to high diversity of the dominant late-successional perennials may notably increase the ability of these lands to contribute to climate change mitigation via $C$ sequestration ${ }^{35}$. High-diversity restorations on abandoned and degraded lands may provide other environmental benefits, including reduced nitrate leaching ${ }^{36}$, reduced year-to-year variability in biomass harvests $^{37}$, fewer invasive plant species ${ }^{38}$, and lower soil $\mathrm{N}_{2} \mathrm{O}$ emissions ${ }^{39,40}$. Restorations also provide habitat that might help lower extinction risks ${ }^{41}$. Another climate moderation benefit could occur if aboveground biomass from degraded and abandoned agricultural lands were harvested for bioenergy production $^{42-44}$. In total, the restoration of high-diversity ecosystems on degraded and abandoned lands merits further consideration for its potential to provide multiple ecological and environmental benefits, including increased carbon capture and sequestration.

\section{Methods}

Experimental design. Our experiment was located in an abandoned agricultural field at Cedar Creek Ecosystem Science Reserve, Minnesota, USA ${ }^{25}$. In 1993, the field was treated with the herbicide glyphosate and then burned once its herbaceous vegetation had died, had the top 6-8 cm of soil removed to reduce seed bank, and was plowed and repeatedly harrowed. In 1994, 168 plots were established, each $13 \mathrm{~m} \times 13 \mathrm{~m}$ (later reduced to $9 \mathrm{~m} \times 9 \mathrm{~m}$ ). They were randomly selected for restoration to 1 of 5 different diversity treatments: planted with $1,2,4,8$, or 16 perennial grassland/savanna species. Species in each plot were randomly selected from a set of 16 grassland species composed of 4 species in each of 4 different functional groups: C4 grass species, C3 grass species, legume species, and nonlegume herbaceous forb species. In addition, two different species of savanna oaks were included in this set, but annual spring burns caused these oaks to be extremely rare, and then lost from the experiment (Supplementary Table 12). All plots received $10 \mathrm{~g} \mathrm{~m}^{-2}$ of seed in May 1994 and $5 \mathrm{~g} \mathrm{~m}^{-2}$ in May 1995, with seed mass divided equally among the species planted in a given plot. Plots were burned annually in spring before growth began to imitate natural fires that were common in these grasslands. Plots have never been fertilized and have been weeded three or four times a year to maintain the intended species compositions and diversity. Current species richness and diversity, as indicated by the effective number of species $^{45,46}$, are highly corrected with the number of plant diversity $\left(r^{2}=0.64\right.$; 
Supplementary Fig. 3). Additional details on the experiment design have been published previously ${ }^{24,25,47}$.

Soil C samples from the upper $0-20 \mathrm{~cm}$ soil depth and $2.5 \mathrm{~cm}$ in diameter, were collected, in each of 9 sites per plot, 5 times throughout the project-in 1994 before planting, 2000, 2004, 2006, and 2015. Additional soil C samples to $60 \mathrm{~cm}$ of depth were collected in 1994, 2006, and 2015. The samples for each plot were first sieved to remove roots; the nine samples per plot were then combined, by depth, mixed, dried, mixed again, and then subsampled for grinding and archiving. Before analysis for total $\mathrm{C}$, they were dried again for 5 days in glass vials, and analyzed for total C by combustion and gas chromatography (Costech ECS 4010 Analyzer, Costech Analytical Technologies Inc., Valencia, CA). Soil dry weights and bulk density were determined after drying soils at $105^{\circ} \mathrm{C}$.

Below-ground biomass between 0 and $30 \mathrm{~cm}$ was periodically sampled over the past 24 years (Fig. 2a) via collection of 12 soil cores, $5 \mathrm{~cm}$ in diameter, evenly spaced across each plot. Deeper soil samples, $30-60 \mathrm{~cm}$ deep, were similarly collected in 2006, 2015, and 2017. Roots in the cores were separated from soil by rinsing on a fine mesh screen with a gentle water shower until the soil largely had been removed. The bare roots were then dried at $40^{\circ} \mathrm{C}$, placed in a sieve to retain roots and dislodge any remaining soil. The clean dried roots were weighed. Root C was calculated as $40 \%$ of the dry biomass, based on analyses of a subset using the Costech ECS 4010 Analyzer.

Bulk density measurement. We measured bulk density in June, 2017, in 87 plots that had been chosen in a stratified-random sampling design for each level of the species diversity treatment. In particular, we randomly chose 16 plots planted with 2 species, and 15,15 , and 15 plots planted with 4,8 , and 16 species richness, respectively. We chose 26 monoculture plots randomly but subject to the constraint that 2 plots were chosen for each of the 12 herbaceous grassland species that have persisted at higher abundances since the initial planting. To measure bulk density, one core per plot was taken to a depth of $60 \mathrm{~cm}$ using an AMS Inc. (American Falls, ID, USA) split soil core sampler with a removal jack (part numbers 400.99, 403.41, $403.73,211.05$, and 211.06). To prevent sand from making it difficult to separate the parts of the corer, polytetrafluoroethylene thread seal tape was used to wrap all threads each time, and then was carefully removed. Each core was taken $>1 \mathrm{~m}$ from the outside of the plot to avoid an edge effect. Upon removal, the sampler was split open and the soil core was cut into three sections: $0-20,20-40$, and $40-60 \mathrm{~cm}$. These soil sections were then placed in resealable plastic bags before drying. In some cases, a small amount of soil was lost from the bottom of the core and the length of the remaining core was used for volume calculations. Most cores remained intact due to recent rains, negating the need to use the excavation method. When soil was lost from the bottom of a core, we assumed, based on a previous soil survey ${ }^{48}$, that bulk density was constant and independent of depth for depths greater than $40 \mathrm{~cm}$. For a subset of plots, the total length of the whole core was compared with the depth of the hole to estimate compaction. There was a mean compaction of $4.5 \%$. An ordinary least squares regression was conducted with compaction as the $y$-variable and species richness as the $x$ variable and there was no relationship $\left(F_{1,81}=0.004, P=0.948\right)$. We also had tested the excavation method (a plastic sheet was used to line a hole after a core at each depth was taken and then filled with a known volume of water), and decided not use it because it had greater variance. After sample collection, the complete sample from each depth was dried in aluminum bread tins in an industrial drying oven at $105^{\circ} \mathrm{C}$ and then weighed. The final dry weight was used to calculate bulk density at each sampling depth using the appropriate volume. For final calculations, a diameter of $4.8 \mathrm{~cm}$ representing the inside sleeve of the corer was used for the final volume calculation. Supplementary Table 13 summarizes mean bulk density results for different species combinations at different depths.

Estimates of soil C stocks. We used the measured mean bulk density for each diversity treatment (Supplementary Table 13), together with soil C concentration, to estimate soil C stocks in 1994, 2006, and 2015. For the $20-60 \mathrm{~cm}$ of soil, we applied the standard fixed depth approach assuming a constant bulk density for each species diversity level. For the $0-20 \mathrm{~cm}$ of soil, we applied the equivalent soil mass approach ${ }^{49-51}$ to account for bulk density changes in this layer of soil given the substantial increase in soil C concentration ${ }^{52,53}$, especially for the high-diversity plots (Supplementary Tables 2 and 13; Supplementary Fig. 4). Earlier measurements of bulk density in this field and experiment ${ }^{20,24,48}$, and the analyses of Supplementary Fig. 4, give a bulk density of the $0-20 \mathrm{~m} \mathrm{~cm}$ depth soil in this field at the time of planting of $1.5 \mathrm{~g} \mathrm{~cm}^{-3}$. Next, we estimated the bulk density in 2006 based on the observed linear decrease in bulk density, as calculated in Supplementary Fig. 4a. Last, we estimated the additional depth needed in 2006 and 2015 to make the soil mass in each year equivalent to that in 1994 for the top $20 \mathrm{~cm}$ soil, assuming the soil bulk density and soil $\mathrm{C}$ concentration for the additional depth equal the mean of those for the $0-20 \mathrm{~cm}$ and $20-40 \mathrm{~cm}$ soil profiles. Estimates of soil C stocks in 2006 and 2015 are summarized in Supplementary Table 3.

Statistical analysis. In this study, we used the linear mixed model (Restricted Maximum Likelihood, JMP Pro 13.1) for variables involving multiple measurements per plot over time, with plot as a random effect and year as a variable. For these models we report the fixed effect tests for different variables. We used multiple regression in other analyses. All figures were made using R (https://www. r-project.org/). Statistical information is provided throughout the text and in figure captions and Supplementary Tables.

\section{Data availability}

All data used in our analyses can be found at the Cedar Creek Ecosystem Science Reserve website, http://www.cedarcreek.umn.edu/research/data. Data on the multi-diversity restoration are part of the "e120" experiment of the Cedar Creek Long-Term Ecological Research program; data on natural succession are from the "e014" and "e054" experiments. Data on soil C concentration for the 32-species plots are from the "e248" experiment.

Received: 9 April 2018 Revised: 8 January 2019 Accepted: 18 January 2019

Published online: 12 February 2019

\section{References}

1. Lal, R. Soil carbon sequestration impacts on global climate change and food security. Science 304, 1623-1627 (2004).

2. Wei, X., Shao, M., Gale, W. \& Li, L. Global pattern of soil carbon losses due to the conversion of forests to agricultural land. Sci. Rep. 4, 4062 (2015).

3. Davidson, E. A. \& Ackerman, I. L. Changes in soil carbon inventories following cultivation of previously untilled soils. Biogeochemistry 20, 161-193 (1993).

4. Lal, R. World cropland soils as a source or sink for atmospheric carbon. Adv. Agron. 71, 145-191 (2001).

5. Sanderman, J., Hengl, T. \& Fiske, G. J. Soil carbon debt of 12,000 years of human land use. Proc. Natl Acad. Sci. 114, 9575-9580 (2017).

6. Olivier, J. G. J., Janssens-Maenhout, G., Muntean, M. \& Peters, J. A. H. W. Trends in Global $\mathrm{CO}_{2}$ Emissions; 2016 Report (PBL Netherlands Environmental Assessment Agency, European Commission, Joint Research Centre, Neatherlands, 2016).

7. Lal, R. Soil carbon sequestration to mitigate climate change. Geoderma 123, 1-22 (2004)

8. Minasny, B. et al. Soil carbon 4 per mille. Geoderma 292, 59-86 (2017).

9. Novara, A. et al. Agricultural land abandonment in Mediterranean environment provides ecosystem services via soil carbon sequestration. Sci. Total Environ. 576, 420-429 (2017).

10. Deng, L., Shangguan, Z.-P. \& Sweeney, S. Changes in soil carbon and nitrogen following land abandonment of farmland on the Loess Plateau, China. PLoS ONE 8, e71923 (2013).

11. Schierhorn, F. et al. Post-Soviet cropland abandonment and carbon sequestration in European Russia, Ukraine, and Belarus: abandonment and carbon sequestration. Glob. Biogeochem. Cycles 27, 1175-1185 (2013).

12. Silver, W. L., Ostertag, R. \& Lugo, A. E. The potential for carbon sequestration through reforestation of abandoned tropical agricultural and pasture lands. Restor. Ecol. 8, 394-407 (2000).

13. Campbell, J. E., Lobell, D. B., Genova, R. C. \& Field, C. B. The global potential of bioenergy on abandoned agriculture lands. Environ. Sci. Technol. 42, 5791-5794 (2008).

14. Post, W. M. \& Kwon, K. C. Soil carbon sequestration and land-use change: processes and potential. Glob. Change Biol. 6, 317-327 (2000).

15. Knops, J. M. H. \& Tilman, D. Dynamics of soil nitrogen and carbon accumulation for 61 years after agricultural abandonment. Ecology 81, 88-98 (2000).

16. Burke, I. C., Lauenroth, W. K. \& Coffin, D. P. Soil organic matter recovery in semiarid grasslands: implications for the conservation reserve program. Ecol. Appl. 5, 793-801 (1995).

17. Wang, B., Liu, G. B., Xue, S. \& Zhu, B. Changes in soil physico-chemical and microbiological properties during natural succession on abandoned farmland in the Loess Plateau. Environ. Earth Sci. 62, 915-925 (2011).

18. Klopf, R. P., Baer, S. G., Bach, E. M. \& Six, J. Restoration and management for plant diversity enhances the rate of belowground ecosystem recovery. Ecol. Appl. 27, 355-362 (2017).

19. Inouye, R. S. et al. Old-field succession on a Minnesota sand plain. Ecology 68, 12-26 (1987).

20. Knops, J. M. H. \& Bradley, K. L. Soil carbon and nitrogen accumulation and vertical distribution across a 74-year chronosequence. Soil Sci. Soc. Am. J. 73, 2096 (2009).

21. Gleeson, S. K. \& Tilman, D. Allocation and the transient dynamics of succession on poor soils. Ecology 71, 1144-1155 (1990).

22. Wedin, D. \& Tilman, D. Competition among grasses along a nitrogen gradient: initial conditions and mechanisms of competition. Ecol. Monogr. 63, 199-229 (1993). 
23. Tilman, D. \& Wedin, D. Plant traits and resource reduction for five grasses growing on a nitrogen gradient. Ecology 72, 685-700 (1991).

24. Fornara, D. A. \& Tilman, D. Plant functional composition influences rates of soil carbon and nitrogen accumulation. J. Ecol. 96, 314-322 (2008).

25. Tilman, D. Diversity and productivity in a long-term grassland experiment. Science 294, 843-845 (2001).

26. Jackson, R. B. et al. The ecology of soil carbon: pools, vulnerabilities, and biotic and abiotic controls. Annu. Rev. Ecol. Evol. Syst. 48, 419-445 (2017).

27. van der Heijden, M. G. A. et al. 'Sampling Effect', a problem in biodiversity manipulation? A reply to David A. Wardle. Oikos 87, 408 (1999).

28. Tilman, D. The influence of functional diversity and composition on ecosystem processes. Science 277, 1300-1302 (1997).

29. Abernathy, J. E., Graham, D. R. J., Sherrard, M. E. \& Smith, D. D. Productivity and resistance to weed invasion in four prairie biomass feedstocks with different diversity. GCB Bioenergy 8, 1082-1092 (2016).

30. Blumenthal, D. M., Jordan, N. R. \& Svenson, E. L. Weed control as a rationale for restoration: the example of tallgrass prairie. Conserv. Ecol. 7, 6 (2003).

31. Dong, S. K., Long, R. J., Hu, Z. Z. \& Kang, M. Y. Productivity and persistence of perennial grass mixtures under competition from annual weeds in the alpine region of the Qinghai-Tibetan Plateau. Weed Res. 45, 114-120 (2005).

32. Poeplau, C. \& Don, A. Soil carbon changes under Miscanthus driven by $\mathrm{C}_{4}$ accumulation and $\mathrm{C}_{3}$ decompostion-toward a default sequestration function. GCB Bioenergy 6, 327-338 (2014).

33. Ewel, J. J. \& Putz, F. E. A place for alien species in ecosystem restoration. Front. Ecol. Environ. 2, 354 (2004).

34. Pittman, S. E. et al. Mitigating the potential for invasive spread of the exotic biofuel crop, Miscanthus $\times$ giganteus. Biol. Invasions 17, 3247-3261 (2015).

35. De Deyn, G. B. et al. Additional carbon sequestration benefits of grassland diversity restoration: soil C sequestration and diversity restoration. J. Appl. Ecol. 48, 600-608 (2011).

36. Dijkstra, F. A., West, J. B., Hobbie, S. E., Reich, P. B. \& Trost, J. Plant diversity, $\mathrm{CO}_{2}$, and $\mathrm{N}$ influence inorganic and organic $\mathrm{N}$ leaching in grasslands. Ecology 88, 490-500 (2007).

37. Tilman, D., Reich, P. B. \& Knops, J. M. H. Biodiversity and ecosystem stability in a decade-long grassland experiment. Nature 441, 629-632 (2006).

38. Kennedy, T. A. et al. Biodiversity as a barrier to ecological invasion. Nature 417, 636-638 (2002)

39. Duran, B. E. L., Duncan, D. S., Oates, L. G., Kucharik, C. J. \& Jackson, R. D. Nitrogen fertilization effects on productivity and nitrogen loss in three grass-based perennial bioenergy cropping systems. PLOS ONE 11, e0151919 (2016).

40. Ribas, A. et al. Plant identity and evenness affect yield and trace gas exchanges in forage mixtures. Plant Soil 391, 93-108 (2015).

41. Lichtenberg, E. M. et al. A global synthesis of the effects of diversified farming systems on arthropod diversity within fields and across agricultural landscapes. Glob. Change Biol. 23, 4946-4957 (2017).

42. Gelfand, I. et al. Sustainable bioenergy production from marginal lands in the US Midwest. Nature 493, 514-517 (2013).

43. Nackley, L. L. et al. Bioenergy that supports ecological restoration. Front. Ecol. Environ. 11, 535-540 (2013).

44. Awasthi, A., Singh, K. \& Singh, R. P. A concept of diverse perennial cropping systems for integrated bioenergy production and ecological restoration of marginal lands in India. Ecol. Eng. 105, 58-65 (2017).

45. Jost, L. Partitioning diversity into independent alpha and beta components. Ecology 88, 2427-2439 (2007).

46. Jost, L. Entropy and diversity. Oikos 113, 363-375 (2006).

47. Tilman, D., Hill, J. \& Lehman, C. Carbon-negative biofuels from low-input high-diversity grassland biomass. Science 314, 1598-1600 (2006).

48. Grigal, D. F., Chamberlain, L. M., Finney, H. R., Wroblewski, D. V. \& Gross, E. R. Soils of the Cedar Creek National History Area (Agricultural Experiment Station, University of Minnesota, USA, 1974).
49. Ellert, B. H. \& Bettany, J. R. Calculation of organic matter and nutrients stored in soils under contrasting management regimes. Can. J. Soil Sci. 75, 529-538 (1995).

50. Gifford, R. M. \& Roderick, M. L. Soil carbon stocks and bulk density: spatial or cumulative mass coordinates as a basis of expression? Glob. Change Biol. 9 , 1507-1514 (2003).

51. Mikha, M. M., Benjamin, J. G., Halvorson, A. D. \& Nielsen, D. C. Soil carbon changes influenced by soil management and calculation method. Open J. Soil Sci. 03, 123-131 (2013).

52. Ruehlmann, J. \& Körschens, M. Calculating the effect of soil organic matter concentration on soil bulk density. Soil Sci. Soc. Am. J. 73, 876 (2009).

53. Schrumpf, M., Schulze, E. D., Kaiser, K. \& Schumacher, J. How accurately can soil organic carbon stocks and stock changes be quantified by soil inventories? Biogeosciences 8, 1193-1212 (2011).

54. Fornara, D. A., Tilman, D. \& Hobbie, S. E. Linkages between plant functional composition, fine root processes and potential soil $\mathrm{N}$ mineralization rates. $J$. Ecol. 97, 48-56 (2009).

\section{Acknowledgments}

We thank the Global Climate and Energy Project (GCEP) and the NSF LTER program (DEB-0620652 and DEB-1234162) for funding this research, Troy Mielke for coordinating data collection, and Dan Bahauddin for data management.

\section{Author contributions}

Y.Y. led the data analysis and writing efforts. D.T. established the experiment, contributed to data analysis and writing, and obtained NSF funding. G.F. measured soil bulk density and contributed to data analysis and writing. C.L. obtained GCEP funding and contributed to writing.

\section{Additional information}

Supplementary Information accompanies this paper at https://doi.org/10.1038/s41467019-08636-w.

Competing interests: The authors declare no competing interests.

Reprints and permission information is available online at http://npg.nature.com/ reprintsandpermissions/

Journal peer review information: Nature Communications thanks the anonymous reviewers for their contribution to the peer review of this work. Peer reviewer reports are available.

Publisher's note: Springer Nature remains neutral with regard to jurisdictional claims in published maps and institutional affiliations.

Open Access This article is licensed under a Creative Commons Attribution 4.0 International License, which permits use, sharing, adaptation, distribution and reproduction in any medium or format, as long as you give appropriate credit to the original author(s) and the source, provide a link to the Creative Commons license, and indicate if changes were made. The images or other third party material in this article are included in the article's Creative Commons license, unless indicated otherwise in a credit line to the material. If material is not included in the article's Creative Commons license and your intended use is not permitted by statutory regulation or exceeds the permitted use, you will need to obtain permission directly from the copyright holder. To view a copy of this license, visit http://creativecommons.org/ licenses/by/4.0/.

(c) The Author(s) 2019 